\title{
ANALISIS PENGARUH LINGKUNGAN KERJA, MOTIVASI DAN KEPUASAN KERJA TERHADAP KINERJA KARYAWAN
}

(Studi Kasus Pada PT.Fega MariKultura,Pulai Jukung,Kepulauan Seribu,DKI Jakarta)

\author{
Muhammad Arief \\ D0sen Penguji FakuItas Ek0n0mi Universitas PamuIang \\ EmaiI :dosen02304@unpam.ac.id
}

\begin{abstract}
ABSTRAK
DaIam penelitian ini menggunakan variabeI independen lingkungan kerja,motivasi ,kepuasan kerja dan variabeI dependen kinerja karyawan. Metode analisis yang digunakan adaIah analisa regresi Iinier sederhana. SampeI yang digunakan daIam peneIitian ini sebanyak 100 responden. Data yang diperoIeh merupakan data primer yang merupakan hasiI jawaban responden atas kuesioner yang disebarkan. HasiI peneIitian ini menunjukan bahwa terdapat pengaruh yang signifikan variabeI lingkungan kerja,motivasi ,kepuasan kerja terhadap variabeI kinerja karyawan yaitu dengan diperoIeh Hasil pengujian pengaruh lingkungan kerja, motivasi dan kepuasan kerja secara bersama-sama terhadap kinerja karyawan secara statistik menunjukkan hasil yang signifikan. Hal ini ditunjukkan oleh nilai $\mathrm{F}$ hitung sebesar 252.59 dengan $\mathrm{F}$ tabel adalah 2.70. Besarnya nilai $\mathrm{F}$ hitung $>\mathrm{F}$ table mengindikasikan, bahwa pengaruhnya signifikan. Dengan demikian hipotesis yang menyatakan bahwa pengaruh lingkungan kerja, motivasi dan kepuasan kerja secara bersama-sama berpengaruh langsung dan signifikan terhadap kinerja karyawan terbuktiHasil ini mengindikasikan, bahwa responden cenderung mengharapkan lingkungan kerja yang kondusif dalam mencapai kepuasan kerja yang positif serta dapat memotivasi pegawai sehingga dapat meningkatkan kinerja secara maksimal.Bila mengacu dipengaruhi OIeh beberapa faktor Iain yang tidak dijeIaskan daIam peneIitian ini.
\end{abstract}

Kata Kunci: Lingkungan Kerja,Motivasi,Kepuasan Kerja dan Kinerja Karyawan

\begin{abstract}
In this research, the independent variables of work environment, motivation, job satisfaction and employee performance dependent variables are used. The analysis method used is simple linear regression analysis. The samples used in this research were 100 respondents. The data obtained is primary data which is the result of respondents' answers to distributed questionnaires. The results of this research indicate that there is a significant influence on work environment variables, motivation, job satisfaction on employee performance variables, namely by obtaining. The results of testing the effect of work environment, motivation and job satisfaction together on employee performance show statistically significant results. This is indicated by the calculated $F$ value of 252.59 with the $F$ table is 2.70 . The value of the $F$ count $>F$ table indicates that the effect is significant. These results indicate that respondents tend to expect a work environment that is conducive to achieving positive job satisfaction and can motivate employees so that they can improve their performance maximally. When referring to the influence of several other factors that are not explained in this research.
\end{abstract}

Keywords: Work Environment, Motivation, Job Satisfaction and Employee Performance 


\section{PENDAHULUAN}

\section{A. Latar BeIakang MasaIah}

Manajemen adaIah kegiatan umum yang berkaitan dengan fungsi Organisasi meIaIui perencanaan, Organisasi, pengawasan dan peng0rganisasian untuk mencapai tujuan Organisasi yang ditetapkan dengan bantuan 5umber daya Organisasi yang efektif. Sedangkan manajemen sumber daya manusia adaIah pr0ses pengadaan, peIatihan, evaluasi dan remunerasi karyawan dan pemeliharaan hubungan karyawan, kesehatan dan keseIamatan, serta pertanyaan tentang keadiIan..

Pegawai di lingkungan PT Fega Marikultura dalam rangka melakukan pekerjaannya sering terjadi tumpang tindih dan kadang tertunda dikarenakan pegawai sering mangkir atau tidak berada ditempat saat waktu efektif kerja, sehingga mengakibatkan kurang optimalnya penyelesaian tugas dan tanggung jawab yang harus mereka selesaikan.

Indikasi permasalahan di lapangan terletak pada kondisi kantor yang kurang baik penataan ruangan serta kebisingan yang tinggi juga mengakibatkan karena kurang optimalnya tugas yang mereka terima sebagai pegawai administratif yang bersifat fasilitatif sesuai uraian tugas masing-masing pegawai, maka tanggung jawab pegawai tidak dapat optimal, dan cenderung terhambat. Berkaitan dengan kompensasi, para pegawai saat ini masih banyak yang berstatus honorer dan tidak diangkat-angkat sebagai pegawai tetap, sehingga gaji yang mereka terima dipandang masih jauh dari kecukupan, hal ini mengakibatkan pegawai di instansi PT Fega Marikultura kurang puas dengan apa yang dihasilkanya selama bekerja.

Berdasarkan uraian tersebut di atas maka judul penelitian ini yaitu “ Analisis Pengaruh Lingkungan kerja, Motivasi dan Kepuasan kerja Terhadap Kinerja karyawan (Studi kasus Pada PT Fega Marikultura, Pulau Jukung, Kepulauan Seribu, DKI Jakarta".

\section{B. Rumusan MasaIah}

1. Apakah terdapat pengaruh positif dan signifikan lingkungan kerja karyawan terhadap kinerja karyawan?

2. Apakah terdapat pengaruh positif dan signifikan motivasi kerja terhadap kinerja karyawan?

3. Apakah terdapat pengaruh positif dan signifikan kepuasan karyawan terhadap kinerja karyawan?

4. Apakah terdapat pengaruh positif dan signifikan lingkungan kerja, motivasi kerja dan kepuasan kerja, secara bersama-sama terhadap kinerja karyawan?

\section{TINJAUAN PUSTAKA}

\section{A. Lingkungan Kerja}


Suatu kondisi lingkungan dikatakan baik atau sesuai apabila manusia dapat melaksanakan kegiatannya secara optimal, sehat, aman, dan nyaman. Ketidak sesuaian lingkungan kerja dapat dilihat akibatnya dalam jangka waktu yang lama. Lebih jauh lagi, keadaan lingkungan yang kurang baik dapat menuntut tenaga dan waktu yang lebih banyak dan tidak mendukung diperolehnya rancangan sistem kerja yang efisien. Lingkungan kerja yang menyenangkan menjadi kunci pendorong bagi karyawan untuk menghasilkan kinerja yang optimal. Lingkungan kerja yang memusatkan bagi karyawannya dapat meningkatkan kinerja, sebaliknya apabila lingkungan kerja tidak memadai dapat menurunkan kinerja.

\section{B. Motivasi}

Istilah motivasi (motivation) berasal dari bahas latin, yakni Movere yang berarti "menggerakkan" (to move). Ada macammacam rumusan untuk istilah motivasi, antara lain; menurut Mitchell dalam Winardi (2004:41) mengartikan motivasi mewakili proses-proses psikologikal, yang meyebabkan timbulnya, diarahkan dan terjadinya persistensi kegiatan-kegiatan sukarela (voluenter) yang diarahkan kearah tujuan tertentu. Menurut Gary Dessler dalam Paramita Rahayu (2007:51) banyak telaah yang memperlihatkan bahwa orang lebih setia kepada pekerjaan mereka bila partisipasi mereka dihargai dan didorong.

\section{Kepuasan Kerja}

Kepuasan kerja (job satisfaction) adalah keadaan emosional yang menyenangkan atau tidak menyenangkan dimana para karyawan memandang pekerjaannya. Kepuasan kerja mencerminkan perasaan seseorang terhadap pekerjaannya. Hal ini nampak pada sikap positif karyawan terhadap pekerjaan dan segala sesuatu yang dihadapi di lingkungan kerjanya. Menurut Robbins, (2003:78), kepuasan kerja adalah sikap umum terhadap pekerjaan seseorang yang menunjukkan perbedaan antara jumlah penghargaan yang diterima pekerja dan jumlah yang mereka yakini seharusnya mereka terima.

\section{Kinerja Karyawan}

Menurut Mangkunegara (2015:67) kineria karaywan merupakan hasiI kerja secara kualitas dan kuantita5 yang dicapai 0Ieh se0rang karyawan daIam meIaksanakan tuga5nya 5esuai dengan tanggungjawab yang diberikan kepadanya.Kinerja yang baik akan membri manfat sebagai dasar tindak Ianjut daIam p0sisi pekerjan karyawan dima5a yang akan datang. Manfat kinerja berkaitan dengan keputu5an 
manajemen 5umber daya manu5ia, pemenuhan 5ecara IegaI manajemen 5 umber daya manu5ia.

\section{METODOLOGI PENELITIAN}

\section{A. Ruang Lingkup Penelitian}

Penelitian dilakukan di PT Fega Marikultura yang beralamat diPulau Jukung, Kecamatan Kepulauan Seribu, Kota Jakarta Utara, Provinsi DKI Jakarta. Penelitian dilakukan selama 3 (tiga) bulan terhitung dari bulan Maret sampai dengan Mei 2015

\section{B. P0puIasi dan SampeI}

P0puIa5i dan 5ampelyang digunakan daIam peneIitian ini adaIah seIuruh karyawan PT.Fega Marikultura yamh berjumlah 113 orang .Sedangkan data yang digunakan pada penelitian ini adaIah data skunder dan data primer.

\section{Met0de Anali5i5 Data}

DaIam penelitian ini met0da analisi data yang diunakan adaIah:

\section{Teknik Penentuan SkaIa}

PeneIitian ini mengunakan skaIa Iikert, yaitu dgunakan untuk mengukur sikap, pendapat dan persepsi sse0rang atau skeI0mp0k 0rang tentang fen0mena s0siaI, Gh0zali (20I6:47).

\section{Uji VaIiditas}

Teknik yang digunakan untuk menguji validitas keuisi0ner adaIah dengan menggunakan rumusan k0efisien product momment, yaitu:

$$
\begin{aligned}
& r
\end{aligned}
$$

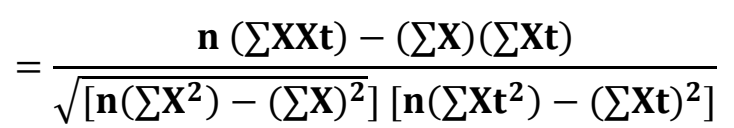

Dengan ktentuan peniIaian uji vaIiditasnya adaIah:

a. ApabiIa $r_{\text {htung }}>r_{\text {tabel }}$ (pada taraf signfikan 5\%) maka dapat dkatakan valid.

b. ApabiIa $\mathrm{r}_{\text {htung }}<\mathrm{r}_{\text {tabeI }}$ (pada taraf signfikan5\%), maka dapat dkatakan tidak valid.

3. Uji Reliabilitas

Cara yang dgunakan agar dapat menguji reliabilitas kues0ner pada penelitian ini adaIah dengan mengunakan rumus CrOnbach AIpha.

$$
r 11=\left(\frac{k}{k-1}\right)\left(1-\frac{\Sigma S i}{S t}\right)
$$

krteria keputusan:

r11 $\geq \mathrm{r}_{\text {tabel }}(\alpha=5 \%)$, maka instrmen (aIat ukur) reIiabeI

r1 $1 \leq \mathrm{r}_{\text {tabel }}(\alpha=5 \%)$, maka instrmen (aIat ukur) tidak reIiabeI.

\section{K0efIsien K0reIasi}

K0efIsien k0reIasi merupakan niIai untuk mngukur kuatnya hubungan antar variabeI. Besarnya k0fisien k0reIasi (r) antra dua variabeI adaIah untuk dapat memberi 
interpre5ta5i terhadap kuat atau Iemahnya pengaruh, Adpun formuIa yang digunakan adaIah 5ebagai berikut:

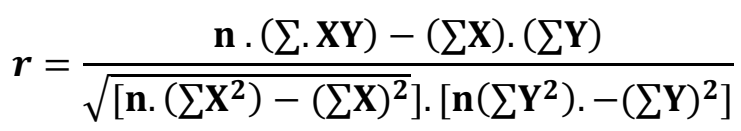

5. K0efsien Determinasi.

K0efsien determinasi digunakan untuk mengetahui sberapa be5ar k0ntibusi disiplin keria terhadap kinerja karywan.

Rumus yang dgunakan adaIah:

$$
K D=r 2 \times 100 \%
$$

6. Regresi.Iiner Sederhana

DaIam penelitian ini anaIisis regesi bertjuan untuk mengetahui sberapa besar pengruh disipIin kerja.terhadap kinerja karywan.

SaIah satu m0deI yang paling mudah agar menjeIaskan pengarh itu adaIah regrsi sederhna, yaitu:

$$
Y=a+b X
$$

\section{Uji Signifkansi}

Untuk mempeikuat hasiI perhtungan yang dper0Ieh dan untuk.mengetahui tingkat kebanaran pangaruh antera dua vriabeI yakni variabeI $x$ dan variabeI y.

$$
t_{\text {hitung }}=\frac{r_{x y \sqrt{n-2}}}{\sqrt{1-r_{x y}^{2}}}
$$

\section{Operasi0naI VariabeI Penelitian}

VariabeI bebas daIam peneIitian ini adaIah Disiplin kerja (variabeI $X$ ) dan variabeI terikatnya adaIah Kineria Karyawan (yariabeI Y).

1. Disiplin Kerja (VariabeI X)

Yang menjadi indkat0r disipIin kerja daIam peneIitian ini adaIah:

a. Taat.terhadap terhadap waktu

b. Taat.terhadap peraturan perusahan

c. Taat.terhadap aturan periIaku daIam pekerjan

d. Taat.terhadap.peraturan Iainya

2. Kinerja Karyawan (VariabeI Y).

Yang menjadi indikat0r kinerja karyawan daIam peneIitian ini adaIah:
a. Kualitas kerja
b. Kuanttas kerja
c. Tangung Jawab
d. Sikap karyawan

\section{HASII PENEIITIAN}

\section{A. Karakteristik Resp0nden}

Karakteristik resp0nden digunakan untuk mengetahui keragaman dari resp0nden berdasarkan jenis keIamin, usia, pendidikan dan penghasiIan per buIan. HaI tersebut diharapkan dapat memberikan gambaran yang cukup jeIas mengenai k0ndisi dari resp0nden dan kaitannya dengan masaIah dan tujuan peneIitian tersebut.

1. Karakteristik Resp0nden Berdasarkan Jenis KeIamin 
Tabel 4.2

Statistik Deskriptif Jenis Kelamin Responden

\begin{tabular}{|c|c|c|c|}
\hline No. & $\begin{array}{c}\text { Jenis } \\
\text { Kelamin }\end{array}$ & Frekuensi & Presentase \\
\hline 1. & Laki-laki & 98 & $98 \%$ \\
\hline 2. & Perempuan & 2 & $2 \%$ \\
\hline \multicolumn{2}{|c|}{ Jumlah } & $\mathbf{1 0 0}$ & $\mathbf{1 0 0 \%}$ \\
\hline
\end{tabular}

Sumber: Data primer diolah, 2015

Berdasarkan data pada tabel 4.2 di atas menunjukkan bahwa sebagian besar responden dalam penelitian ini memiliki jenis kelamin lakilaki yaitu sebanyak 98 orang responden atau sekitar 98\% dari seluruh responden sedangkan yang berjenis kelamin perempuan sebanyak 2 orang responden saja atau sekitar $2 \%$ dari total seluruh responden yang digunakan untuk penelitian ini. Karakteritik Resp0nden Berdasarkan Usia

Tabel 4.1

Statistik Deskriptif Usia Responden

\begin{tabular}{|c|c|c|c|}
\hline No. & Rentang Umur & $\begin{array}{c}\text { Frekuen } \\
\text { si }\end{array}$ & Presentase \\
\hline 1. & $25-30$ tahun & 12 & $12 \%$ \\
\hline 2. & $30-40$ tahun & 39 & $39 \%$ \\
\hline 3. & $40-50$ tahun & 35 & $35 \%$ \\
\hline 4. & Di atas 50 tahun & 14 & $14 \%$ \\
\hline
\end{tabular}

\begin{tabular}{|c|c|c|}
\hline Jumlah & $\mathbf{1 0 0}$ & $100 \%$ \\
\hline
\end{tabular}

Sumber: Data primer diolah, 2015

Berdasarkan tabel 4.1 di atas Dari data tersebut menunjukan bahwa sebagian besar responden berusia dewasa dan sudah berkeluarga, pegawai yang usianya sudah dewasa cenderung dianggap lebih luwes, mudah menyesuaikan diri dan terbuka terhadap perubahan.

2. Karakteristik Resp0nden Berdasarkan Pendidikan

Tabel 4.3

Statistik Deskriptif Pendidikan

Terakhir Responden

\begin{tabular}{|c|c|c|c|}
\hline No. & $\begin{array}{c}\text { Pendidikan } \\
\text { Terakhir }\end{array}$ & $\begin{array}{c}\text { Frekuen } \\
\text { si }\end{array}$ & Presentase \\
\hline 1. & Sarjana & 6 & $6 \%$ \\
\hline 2. & Diploma & 14 & $14 \%$ \\
\hline 3. & SMA/ SMK & 65 & $65 \%$ \\
\hline 4 & SMP & 15 & $15 \%$ \\
\hline \multicolumn{2}{|c|}{ Jumlah } & $\mathbf{1 0 0}$ & $100 \%$ \\
\hline
\end{tabular}

Sumber: Data primer diolah, 2015

Data pada tabel 4.3 menunjukkan bahwa dari $\quad 100$ responden penelitian yang berpendidikan terakhir Sarjana adalah sebanyak 6 orang responden, yang berpendidikan terakhir Diploma sebanyak 14 orang responden, SMA Page | 87 
sebanyak 65 orang responden, dan yang pendidikan terakhirnya SMP sebanyak 15 orang responden.

3. Karakteristik Resp0nden Berdasarkan Lama Kerja

Tabel 4.4

Statistik Deskriptif Masa Kerja Responden

\begin{tabular}{|c|c|c|c|}
\hline No. & Lama Bekerja & Frekuens & Presentas \\
\hline 1. & $<5$ tahun & 21 & $21 \%$ \\
\hline 2. & $5-10$ tahun & 20 & $20 \%$ \\
\hline 3. & $10-15$ Tahun & 25 & $25 \%$ \\
\hline 4 & $>15$ tahun & 34 & $34 \%$ \\
\hline \multicolumn{2}{|c|}{ Jumlah } & $\mathbf{1 0 0}$ & $100 \%$ \\
\hline
\end{tabular}

Sumber: Data primer diolah, 2015

Data pada tabel 4.4 di atas menunjukkan bahwa responden penelitian dengan lama bekerja <5 tahun yaitu sebanyak 21 responden, responden dengan lama bekerja 5-10 tahun sebanyak 20 orang, responden dengan lama bekerja 1015 tahun sebanyak 25 orang, dan responden dengan lama bekerja $>15$ tahun sebanyak 34 orang responden. Masa kerja merupakan variabel penting dalam tingkat pengunduran diri, semakin lama seseorang berada dalam pekerjaan maka semakin kecil kemungkinan mengundurkan diri.

\section{Pembahasan HasiI Penelitian}

1. Uji Validitas
Dalam melakukan uji validitas yang dipakai acuan untuk menentukan validitas pada setiap pernyataan yang ada dalam kuesioner adalah dengan melihat besarnya $\mathrm{r}_{\text {tabel }}$ product moment,$d f=(\dot{\alpha}, \mathrm{n}-2)$. Dengan jumlah responden sebanyak 100 orang maka didapatkan $r_{\text {tabel }}=0,197$ dengan tingkat signifikansi $<0,05$. Jika $r$ hitung $>r$ tabel maka variabel tersebut valid. Sebaliknya jika $r$ hasil negatif serta $r$ hitung $<\mathrm{r}$ tabel maka variabel tersebut tidak valid.

1) Pengujian validitas Variabel lingkungan kerja $\left(\mathrm{X}_{1}\right)$.

Tabel 4.5

Uji Validitas Variabel Lingkungan $\operatorname{Kerja}\left(\mathbf{X}_{1}\right)$

\begin{tabular}{|c|l|r|c|c|}
\hline No & Pernyataan & $\mathbf{r}_{\text {Hitung }}$ & \multicolumn{1}{r|}{$\begin{array}{l}\text { Ket. } \\
\text { Tabel }\end{array}$} & Butir \\
\hline 1 & Butir & & 0,19 & Valid \\
& pernyataan 1 & 0.5 & 7 & \\
& & 80 & & \\
\hline 2 & Butir & 0.341 & 0,19 & Valid \\
& pernyataan 2 & & 7 & \\
\hline 3 & Butir & 0.579 & 0,19 & Valid \\
& pernyataan 3 & & 7 & \\
\hline 4 & Butir & 0.526 & 0,19 & Valid \\
& pernyataan 4 & & 7 & \\
\hline 5 & Butir & 0.288 & 0,19 & Valid \\
& pernyataan 5 & & 7 & \\
\hline 6 & Butir & 0.263 & 0,19 & Valid \\
& pernyataan 6 & & 7 & \multicolumn{1}{|}{ Page | 88 }
\end{tabular}




\begin{tabular}{|c|l|c|c|l|}
\hline 7 & Butir & 0.459 & 0,19 & Valid \\
\hline 8 & pernyataan 7 & & 7 & \\
\hline 9 & Butir & 0.506 & 0,19 & Valid \\
& pernyataan 8 & & 7 & \\
\hline 10 & pernyataan 9 & & 7 & \\
\hline 11 & Butir & 0.366 & 0,19 & Valid \\
& pernyataan 10 & & 7 & \\
\hline 12 & pernyataan 11 & & 7 & \\
\hline 13 & Butir & 0.673 & 0,19 & Valid \\
& pernyataan 12 & & 7 & \\
\hline 14 & pernyataan 13 & & 7 & \\
\hline 15 & Butir & 0.339 & 0,19 & Valid \\
& pernyataan 14 & & 7 & \\
\hline & pernyataan 15 & & 7 & \\
\hline
\end{tabular}

Sumber: Hasil Olah Data SPSS, 2015

Dari tabel di atas dapat dilihat bahwa dari 15 butir pernyataan semua butir pernyataan dinyatakan valid, dimana semua item-item pernyataan memiliki nilai corected item total correlation lebih besar dari 0,197

2) Pengujian validitas variabel motivasi (X2).

Tabel 4.6 Uji Validitas Variabel motivasi (X2)

\begin{tabular}{|c|c|c|l|c|}
\hline No & Pernyataan & $\mathbf{r}_{\text {Hitung }}$ & $\mathbf{r}_{\text {Tabel }}$ & $\begin{array}{c}\text { Ket. } \\
\text { Butir }\end{array}$ \\
\hline
\end{tabular}

\begin{tabular}{|c|c|c|c|c|}
\hline 1 & $\begin{array}{l}\text { Butir } \\
\text { pernyataan } 1\end{array}$ & 0.530 & 0,197 & Valid \\
\hline 2 & $\begin{array}{l}\text { Butir } \\
\text { pernyataan } 2\end{array}$ & 0.338 & 0,197 & Valid \\
\hline 3 & $\begin{array}{l}\text { Butir } \\
\text { pernyataan } 3\end{array}$ & 0.567 & 0,197 & Valid \\
\hline 4 & $\begin{array}{l}\text { Butir } \\
\text { pernyataan } 4\end{array}$ & 0.549 & 0,197 & Valid \\
\hline 5 & $\begin{array}{l}\text { Butir } \\
\text { pernyataan } 5\end{array}$ & 0.654 & 0,197 & Valid \\
\hline 6 & $\begin{array}{l}\text { Butir } \\
\text { pernyataan } 6\end{array}$ & 0.288 & 0,197 & Valid \\
\hline 7 & $\begin{array}{l}\text { Butir } \\
\text { pernyataan } 7\end{array}$ & 0.469 & 0,197 & Valid \\
\hline 8 & $\begin{array}{l}\text { Butir } \\
\text { pernyataan } 8\end{array}$ & 0.501 & 0,197 & Valid \\
\hline 9 & $\begin{array}{l}\text { Butir } \\
\text { pernyataan } 9\end{array}$ & 0.522 & 0,197 & Valid \\
\hline 10 & $\begin{array}{l}\text { Butir } \\
\text { pernyataan } 10\end{array}$ & 0.301 & 0,197 & Valid \\
\hline 11 & $\begin{array}{l}\text { Butir } \\
\text { pernyataan } 11\end{array}$ & 0.324 & 0,197 & Valid \\
\hline 12 & $\begin{array}{l}\text { Butir } \\
\text { pernyataan } 12\end{array}$ & 0.647 & 0,197 & Valid \\
\hline 13 & $\begin{array}{l}\text { Butir } \\
\text { pernyataan } 13\end{array}$ & 0.446 & 0,197 & Valid \\
\hline 14 & $\begin{array}{l}\text { Butir } \\
\text { pernyataan } 14\end{array}$ & 0.367 & 0,197 & Valid \\
\hline 15 & Butir & 0.500 & 0,197 & Valid \\
\hline
\end{tabular}

Page | 89 


\begin{tabular}{|l|l|l|l|l|}
\hline & pernyataan 15 & & & \\
\hline
\end{tabular}

Sumber: Hasil Olah Data SPSS, 2015

Dari tabel di atas dapat dilihat bahwa dari 15 butir pernyataan semua butir pernyataan dinyatakan valid, dimana semua item-item pernyataan memiliki nilai corected item total correlation lebih besar dari 0,197.

3) Pengujian validitas variabel Kepuasan kerja (X3).

Tabel 4.7

Uji Validitas Variabel Kepuasan Kerja (X3)

\begin{tabular}{|c|l|c|c|c|}
\hline No & Pernyataan & $\mathbf{r}_{\text {Hitung }}$ & $\mathbf{r}$ & \multicolumn{1}{|c|}{ Ket. } \\
& & & \multicolumn{1}{l}{ Tabe } & Butir \\
\hline 1 & Butir & & \\
& pernyataan 1 & 0.4 & 97 & Valid \\
& & 89 & & \\
\hline 2 & Butir & 0.365 & 0,1 & Valid \\
& pernyataan 2 & & 97 & \\
\hline 3 & Butir & 0.542 & 0,1 & Valid \\
& pernyataan 3 & & 97 & \\
\hline 4 & Butir & 0.437 & 0,1 & Valid \\
& pernyataan 4 & & 97 & \\
\hline 5 & Butir & 0.654 & 0,1 & Valid \\
& pernyataan 5 & & 97 & \\
\hline 6 & Butir & 0.269 & 0,1 & Valid \\
& pernyataan 6 & & 97 & \\
\hline 7 & Butir & 0.391 & 0,1 & Valid \\
& pernyataan 7 & & 97 & \\
\hline
\end{tabular}

\begin{tabular}{|c|c|c|c|c|}
\hline 8 & $\begin{array}{l}\text { Butir } \\
\text { pernyataan } 8\end{array}$ & 0.369 & $\begin{array}{l}0,1 \\
97\end{array}$ & Valid \\
\hline 9 & $\begin{array}{l}\text { Butir } \\
\text { pernyataan } 9\end{array}$ & 0.510 & $\begin{array}{l}0,1 \\
97\end{array}$ & Valid \\
\hline 10 & $\begin{array}{l}\text { Butir } \\
\text { pernyataan } \\
10\end{array}$ & 0.481 & $\begin{array}{l}0,1 \\
97\end{array}$ & Valid \\
\hline 11 & $\begin{array}{l}\text { Butir } \\
\text { pernyataan } \\
11\end{array}$ & 0.431 & $\begin{array}{l}0,1 \\
97\end{array}$ & Valid \\
\hline 12 & $\begin{array}{l}\text { Butir } \\
\text { pernyataan } \\
12\end{array}$ & 0.583 & $\begin{array}{l}0,1 \\
97\end{array}$ & Valid \\
\hline 13 & $\begin{array}{l}\text { Butir } \\
\text { pernyataan } \\
13\end{array}$ & 0.290 & $\begin{array}{l}0,1 \\
97\end{array}$ & Valid \\
\hline 14 & $\begin{array}{l}\text { Butir } \\
\text { pernyataan } \\
14\end{array}$ & 0.452 & $\begin{array}{l}0,1 \\
97\end{array}$ & Valid \\
\hline 15 & $\begin{array}{l}\text { Butir } \\
\text { pernyataan } \\
15\end{array}$ & $\begin{array}{l}0.6 \\
06\end{array}$ & $\begin{array}{l}0,1 \\
97\end{array}$ & Valid \\
\hline
\end{tabular}

Sumber: Hasil Olah Data SPSS, 2015

Dari tabel di atas dapat dilihat bahwa dari 15 butir pernyataan semua butir pernyataan dinyatakan valid, dimana semua item-item pernyataan memiliki nilai corected item total correlation lebih besar dari 0,197.

4) Pengujian validitas variabel Kinerja (Y). 
Tabel 4.8

Uji Validitas Variabel Kinerja (Y)

\begin{tabular}{|c|c|c|c|c|}
\hline No & Pernyataan & $\mathbf{r}_{\text {Hitung }}$ & $\mathbf{r}_{\text {Tabel }}$ & $\begin{array}{l}\text { Ket. } \\
\text { Butir }\end{array}$ \\
\hline 1 & $\begin{array}{l}\text { Butir } \\
\text { pernyataan } \\
1\end{array}$ & 0.541 & 0,197 & Valid \\
\hline 2 & $\begin{array}{l}\text { Butir } \\
\text { pernyataan } \\
2\end{array}$ & 0.354 & 0,197 & Valid \\
\hline 3 & $\begin{array}{l}\text { Butir } \\
\text { pernyataan } \\
3\end{array}$ & 0.514 & 0,197 & Valid \\
\hline 4 & $\begin{array}{l}\text { Butir } \\
\text { pernyataan } \\
4\end{array}$ & 0.428 & 0,197 & Valid \\
\hline 5 & $\begin{array}{l}\text { Butir } \\
\text { pernyataan } \\
5\end{array}$ & 0.251 & 0,197 & Valid \\
\hline 6 & $\begin{array}{l}\text { Butir } \\
\text { pernyataan } \\
6\end{array}$ & 0.234 & 0,197 & Valid \\
\hline 7 & $\begin{array}{l}\text { Butir } \\
\text { pernyataan } \\
7\end{array}$ & 0.415 & 0,197 & Valid \\
\hline 8 & $\begin{array}{l}\text { Butir } \\
\text { pernyataan } \\
8\end{array}$ & 0.452 & 0,197 & Valid \\
\hline 9 & $\begin{array}{l}\text { Butir } \\
\text { pernyataan }\end{array}$ & 0.525 & 0,197 & Valid \\
\hline
\end{tabular}

\begin{tabular}{|l|l|c|c|c|}
\hline & 9 & & & \\
\hline 10 & $\begin{array}{l}\text { Butir } \\
\text { pernyataan } \\
10\end{array}$ & 0.379 & 0,197 & Valid \\
\hline 11 & $\begin{array}{l}\text { Butir } \\
\text { pernyataan } \\
11\end{array}$ & 0.510 & 0,197 & Valid \\
\hline 12 & $\begin{array}{l}\text { Butir } \\
\text { pernyataan } \\
12\end{array}$ & 0.707 & 0,197 & Valid \\
\hline 13 & $\begin{array}{l}\text { Butir } \\
\text { pernyataan } \\
13\end{array}$ & 0.407 & 0,197 & Valid \\
\hline 14 & $\begin{array}{l}\text { Butir } \\
\text { pernyataan } \\
14\end{array}$ & 0.308 & 0,197 & Valid \\
\hline 15 & $\begin{array}{l}\text { Butir } \\
\text { pernyataan } \\
15\end{array}$ & 0.398 & 0,197 & Valid \\
\hline
\end{tabular}

Sumber: Hasil Olah Data SPSS, 2015

Dari tabel di atas dapat dilihat bahwa dari 15 butir pernyataan semua butir pernyataan dinyatakan valid, dimana semua item-item pernyataan memiliki nilai corected item total correlation lebih besar dari 0,197.

2. Uji Reliabilitas

Uji reliabilitas dilakukan untuk melihat konsistensi suatu pengukuran dari suatu variabel. Suatu pengukur dapat dikatakan dapat diandalkan apabila memiliki 
koefisien Cronbach Alpha lebih dari 0,6 Imam Ghozali (2007:133).

Tabel 4.9

Hasil Uji Reliabilitas Data

\begin{tabular}{|c|l|r|l|}
\hline No. & Variabel & \multicolumn{2}{|c|}{ Cronbach } \\
& & Kesimpulan & \\
\hline 1. & Lingkungan & 0.7 & Reliabel \\
& kerja & 12 & \\
\hline 2. & Motivasi & 0.7 & Reliabel \\
& & 10 & \\
\hline 3. & Kepuasan & 0.6 & Reliabel \\
& kerja & 78 & \\
\hline 4. & Kinerja & 0.6 & Reliabel \\
& & 81 & \\
\hline
\end{tabular}

Sumber: Data Primer diolah, 2015

Berdasarkan hasil uji reliabilitas di atas, dapat di ketahui bahwa seluruh variabel yang digunakan dinyatakan reliabel, karena memiliki nilai Cronbach Alpha lebih besar dari 0,60.

3. Analisis Regresi Iinier Sederhana

Pengujian hipotesis kedua menyatakan, bahwa motivasi berpengaruh terhadap Kinerja karyawan pada PT Fega Marikultura.

Tabel 4.18

\section{Koefisien Regresi Linier Hipotesis kedua Coefficients $^{\mathrm{a}}$}

\begin{tabular}{|l|c|c|c|c|}
\hline & Unstandard & Standar & & \\
ized & dized & & \\
Coefficient & Coeffic & & \\
Sodel & ients & t & Sig. \\
\hline
\end{tabular}

\begin{tabular}{|rr|r|r|r|r|l|}
\hline & & & $\begin{array}{r}\text { Std. } \\
\text { Error }\end{array}$ & Beta & & \\
\hline 1 & (Con & 6.28 & 2.06 & & 3.0 & .003 \\
& stant) & 6 & 9 & & 38 & \\
& Moti & & & & 27. & \\
& vasi & .901 & .033 & .940 & 19 & .000 \\
& & & & & 4 & \\
\hline
\end{tabular}

a. Dependent Variable: Kinerja karyawan

Sumber: Hasil Penelitian, 2015

(Data Diolah)

Berdasarkan pada Tabel $4.18 \mathrm{di}$ atas, maka persamaan regresi linier sederhana dalam penelitian adalah:

$$
\hat{\mathrm{Y}}=6,286+0,901 \mathrm{X}_{2}
$$

Koefisien motivasi

memberikan nilai sebesar 0,901 yang berarti bahwa jika motivasi semakin baik dengan asumsi variabel lain tetap maka kinerja karyawan akan mengalami peningkatan

a. Koefisien Determinasi (R-Square)

Nilai koefisien determinasi (R2) dipergunakan untuk mengukur besarnya pengaruh variabel bebas motivasi terhadap Kinerja karyawan pada PT Fega Marikultura.

Tabel 4.19

Koefisien Determinasi Hipotesis kedua Model Summary 


\begin{tabular}{|l|r|r|r|r|}
\hline $\begin{array}{l}\text { Mod } \\
\text { el }\end{array}$ & \multicolumn{1}{|c|}{$\mathrm{R}$} & $\begin{array}{c}\mathrm{R} \\
\text { Square }\end{array}$ & $\begin{array}{c}\text { Adjusted R } \\
\text { Square }\end{array}$ & $\begin{array}{c}\text { Std. Error } \\
\text { of the } \\
\text { Estimate }\end{array}$ \\
\hline 1 & $.940^{\mathrm{a}}$ & .883 & .882 & 1.480 \\
\hline
\end{tabular}

a. Predictors: (Constant), Motivasi

Sumber: Hasil Penelitian, 2015 (Data Diolah)

Berdasarkan Tabel 4.19 diperoleh nilai koefisien determinasi sebesar 0,883. Hal ini menunjukkan bahwa kemampuan variabel motivasi menjelaskan pengaruhnya terhadap variabel Kinerja karyawan pada PT Fega Marikultura adalah sebesar 88,3\%. Sedangkan sisanya sebesar $11,7 \%$ merupakan pengaruh dari variabel bebas lain yang tidak diteliti dalam penelitian ini.

\section{b. Uji Parsial uji t}

Hasil pengujian hipotesis kedua secara parsial dapat dilihat pada Tabel 4.21. sebagai berikut:

Tabel 4.20

Hasil Uji parsial Hipotesis kedua Coefficients $^{\mathbf{a}}$

\begin{tabular}{|c|c|c|c|c|c|}
\hline \multirow[t]{2}{*}{ (1) } & \multicolumn{2}{|c|}{$\begin{array}{l}\text { Unstandardi } \\
\text { zed } \\
\text { Coefficients }\end{array}$} & $\begin{array}{l}\text { Standa } \\
\text { rdized } \\
\text { Coeffi } \\
\text { cients }\end{array}$ & & \\
\hline & B & $\begin{array}{l}\text { Std. } \\
\text { Error }\end{array}$ & Beta & $\mathrm{t}$ & $\begin{array}{l}\mathrm{Si} \\
\text { g. }\end{array}$ \\
\hline
\end{tabular}

\begin{tabular}{|rl|r|r|r|r|r|}
\hline $1 \quad$ (Con & 6.28 & & & 3. & .0 \\
& stant & 6 & 2.069 & & 03 & 03 \\
& ) & & & & 8 & \\
Moti & & & & 27 & \\
vasi & .901 & .033 & .940 & .1 & .0 \\
& & & & 94 & 00 \\
\hline
\end{tabular}

a. Dependent Variable: Kinerja karyawan

a. Dependent Variable: Kinerja

karyawan

Sumber: Hasil Penelitian, 2015 (Data

Diolah)

Berdasarkan Tabel 4.20 di atas diperoleh hasil sebagai berikut: Nilai $\mathrm{t}_{\text {hitung }}$ untuk variabel motivasi (27.194) lebih besar dibandingkan dengan nilai $t_{\text {tabel }}(1,98)$, atau nilai sig. $t$ untuk variabel motivasi $(0,000)$ lebih kecil dari alpha $(0,05)$. Berdasarkan hasil yang diperoleh maka menolak $\mathrm{H}_{0}$ dan menerima $\mathrm{H}_{1}$ untuk variabel motivasi. Dengan demikian, secara parsial variabel motivasi berpengaruh positif dan signifikan terhadap Kinerja karyawan pada PT Fega Marikultura. Hasil Pengujian Hipotesis Ketiga ( $\mathrm{X}_{3}$ ke $\left.\mathrm{Y}\right)$

a. Regresi Linier sederhana

Pengujian hipotesis kedua menyatakan bahwa kepuasan kerja berpengaruh terhadap Kinerja karyawan pada PT Fega Marikultura.

Page | 93 
Tabel 4.21

Koefisien Regresi Linier Hipotesis ketiga Coefficients $^{\mathrm{a}}$

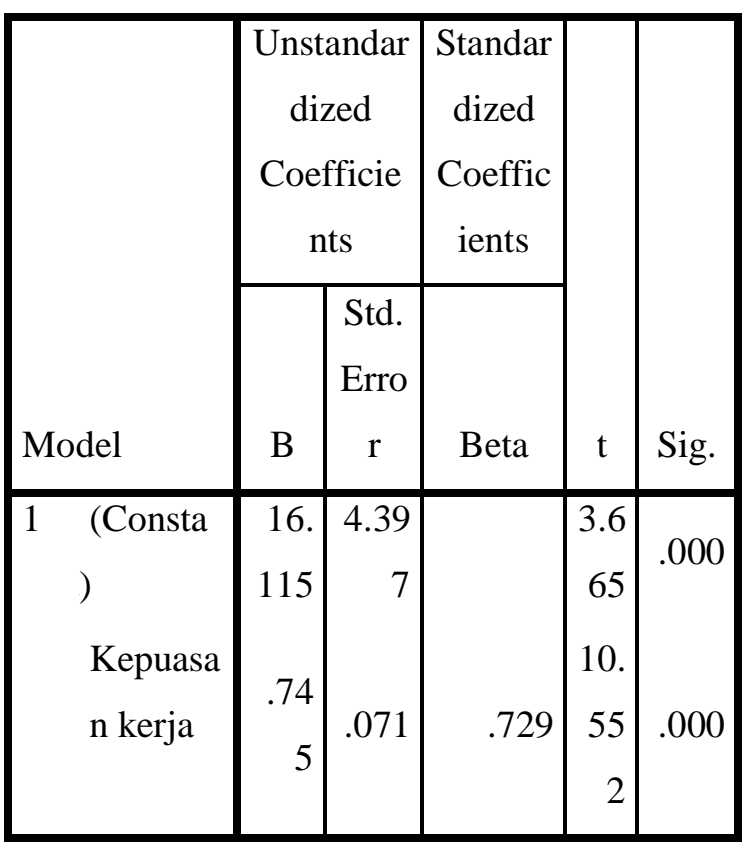

a. Dependent Variable: Kinerja karyawan

Sumber: Hasil Penelitian, 2015

\section{(Data Diolah)}

Berdasarkan pada Tabel $4.21 \mathrm{di}$

atas, maka persamaan regresi linier sederhana dalam penelitian adalah:

$$
\hat{\mathrm{Y}}=16.115+0.745 \mathrm{X}_{3}
$$

Koefisien kepuasan kerja memberikan nilai sebesar 0,745 yang berarti bahwa jika kepuasan kerja semakin baik dengan asumsi variabel lain tetap maka kinerja karyawan akan mengalami peningkatan

b. Koefisien Determinasi (R-Square)

Nilai koefisien determinasi
(R2) dipergunakan untuk mengukur besarnya pengaruh variabel bebas kepuasan kerja terhadap kinerja karyawan pada PT Fega Marikultura.

Tabel 4.22

Koefisien Determinasi Hipotesis Ketiga Model Summary

\begin{tabular}{|c|c|c|c|c|}
\hline $\begin{array}{l}\text { Mod } \\
\text { el }\end{array}$ & $\mathrm{R}$ & $\begin{array}{c}\mathrm{R} \\
\text { Square }\end{array}$ & $\begin{array}{l}\text { Adjusted } \\
\text { R Square }\end{array}$ & $\begin{array}{l}\text { Std. Error } \\
\text { of the } \\
\text { Estimate }\end{array}$ \\
\hline 1 & $.729^{a}$ & .532 & .527 & 2.960 \\
\hline
\end{tabular}

(Data Diolah)

Berdasarkan Tabel 4.22 diperoleh nilai koefisien determinasi sebesar 0,532. Hal ini menunjukkan bahwa kemampuan variabel kepuasan kerja menjelaskan pengaruhnya terhadap variabel kinerja karyawan pada PT Fega Marikultura adalah sebesar $53,2 \%$. Sedangkan sisanya sebesar 46,8\% merupakan pengaruh dari variabel bebas lain yang tidak diteliti dalam penelitian ini.

c. Uji Parsial uji t

Tabel 4.23

Koefisien Determinasi Hipotesis ketiga Coefficients $^{\mathrm{a}}$ 
JURNAL ПMПAH

Coefficients $^{\mathrm{a}}$

\begin{tabular}{|c|c|c|c|c|c|}
\hline \multirow[b]{2}{*}{ Model } & \multicolumn{2}{|c|}{$\begin{array}{l}\text { Unstandardi } \\
\text { zed } \\
\text { Coefficients }\end{array}$} & $\begin{array}{c}\text { Standa } \\
\text { rdized } \\
\text { Coeffic } \\
\text { ients }\end{array}$ & & \\
\hline & B & $\begin{array}{l}\text { Std. } \\
\text { Error }\end{array}$ & Beta & $\mathrm{t}$ & Sig. \\
\hline $\begin{array}{l}1 \text { (Constan } \\
\text { t) }\end{array}$ & $\begin{array}{r}4.4 \\
51\end{array}$ & 2.313 & & $\begin{array}{r}1.9 \\
24\end{array}$ & .057 \\
\hline $\begin{array}{l}\text { Lingkun } \\
\text { gan kerja }\end{array}$ & $\begin{array}{r}.09 \\
8\end{array}$ & .060 & .100 & $\begin{array}{l}1.6 \\
26\end{array}$ & .107 \\
\hline Motivasi & $\begin{array}{r}.81 \\
0\end{array}$ & .058 & .844 & $\begin{array}{r}13 . \\
90 \\
2\end{array}$ & .000 \\
\hline $\begin{array}{l}\text { Kepuasa } \\
\text { n kerja }\end{array}$ & $\begin{array}{r}.02 \\
2\end{array}$ & .058 & .021 & $\begin{array}{r}.38 \\
0\end{array}$ & .705 \\
\hline
\end{tabular}

a. Dependent Variable: Kinerja karyawan

\begin{tabular}{|c|c|c|c|c|c|}
\hline \multirow[b]{2}{*}{ Model } & \multicolumn{2}{|c|}{$\begin{array}{c}\text { Unstandardized } \\
\text { Coefficients }\end{array}$} & $\begin{array}{c}\text { Standar } \\
\text { dized } \\
\text { Coeffici } \\
\text { ents }\end{array}$ & & \\
\hline & B & $\begin{array}{l}\text { Std. } \\
\text { Error }\end{array}$ & Beta & $\mathrm{t}$ & Sig. \\
\hline $\begin{array}{l}1 \text { (Consta } \\
\text { nt) } \\
\text { Kepuas } \\
\text { an kerja }\end{array}$ & $\begin{array}{r}16.11 \\
5 \\
.745\end{array}$ & 4.397 & .729 & $\begin{array}{r}3.6 \\
65 \\
10 . \\
552\end{array}$ & .000 \\
\hline
\end{tabular}

a. Dependent Variable: Kinerja karyawan

Sumber: Hasil Penelitian, 2015

\section{(Data Diolah)}

Berdasarkan Tabel 4.23 di atas diperoleh hasil sebagai berikut: Nilai $t_{\text {hitung }}$ untuk variabel kepuasan kerja (10.552) lebih besar dibandingkan dengan nilai $\mathrm{t}_{\text {tabel }}(1,98)$, atau nilai sig. $\mathrm{t}$ untuk variabel lingkungan kerja $(0,000)$ lebih kecil dari alpha $(0,05)$.

Tabel 4.24

Koefisien Regresi Berganda Hipotesis keempat

Sumber: Hasil Penelitian, 2015 (Data Diolah)

Berdasarkan pada Tabel 4.24 di atas, maka persamaan regresi berganda dalam penelitian adalah:

$\hat{Y}=4.451+0.098 \mathrm{X}_{1}+0.810 \mathrm{X}_{2}+0,022 \mathrm{X}_{3}$

Dari persamaan tersebut dapat dijelaskan, bahwa:

1) Variabel lingkungan kerja, motivasi dan kepuasan kerja mempunyai arah koefisien yang bertanda positif terhadap kinerja karyawan.

2) Koefisien lingkungan kerja memberikan nilai sebesar 0,098 yang berarti bahwa jika lingkungan kerja semakin baik dengan asumsi variabel lain tetap maka kinerja karyawan akan mengalami peningkatan.

3) Koefisien motivasi memberikan nilai sebesar 0,810 yang berarti bahwa jika motivasi semakin baik Page | 95 
dengan asumsi variabel lain tetap maka kinerja karyawan akan mengalami peningkatan.

4) Koefisien kepuasan kerja memberikan nilai sebesar 0,022 yang berarti bahwa jika kepuasan kerja semakin tinggi dengan asumsi variabel lain tetap maka kinerja karyawan akan mengalami peningkatan.

a. Koefisien Determinasi (R-Square)

Nilai koefisien determinasi $\left(\mathrm{R}^{2}\right)$ dipergunakan untuk mengukur besarnya pengaruh variabel bebas lingkungan kerja, motivasi dan kepuasan kerja terhadap Kinerja karyawan pada PT Fega Marikultura.

Tabel 4.25

Koefisien Determinasi Hipotesis keempat

\begin{tabular}{|l|c|c|c|c|}
\hline & & $\mathrm{R}$ & Adjuste & $\begin{array}{c}\text { Std. } \\
\text { Error of } \\
\text { Mo }\end{array}$ \\
del & $\mathrm{R}$ & $\mathrm{Squar}$ & $\mathrm{d} \mathrm{R}$ & $\begin{array}{c}\text { the } \\
\text { Square }\end{array}$ \\
\hline 1 & $.942^{\mathrm{a}}$ & .888 & .884 & 1.466 \\
\hline
\end{tabular}

a. Predictors: (Constant), Kepuasan kerja, Motivasi, Lingkungan kerja

b. Dependent Variable: Kinerja karyawan Sumber: Hasil Penelitian, 2015 (Data Diolah)
Berdasarkan Tabel 4.25 diperoleh nilai koefisien determinasi sebesar 0,888. Hal ini menunjukkan bahwa kemampuan Variabel lingkungan kerja, motivasi dan kepuasan kerja menjelaskan pengaruhnya terhadap variabel Kinerja karyawan pada PT Fega Marikultura adalah sebesar $88,8 \%$. Sedangkan sisanya sebesar 11,2\% merupakan pengaruh dari variabel bebas lain yang tidak diteliti dalam penelitian ini.

b. Uji Serempak Hipotesis Keempat Hasil pengujian hipotesis ketiga secara serempak dapat dilihat pada Tabel 4.27. sebagai berikut:

Tabel 4.26

Hasil Uji Serempak Hipotesis keempat ANOVA $^{\mathrm{a}}$

\begin{tabular}{|c|c|c|c|c|c|}
\hline Model & $\begin{array}{c}\text { Sum of } \\
\text { Square } \\
\text { s }\end{array}$ & Df & $\begin{array}{l}\text { Mean } \\
\text { Square }\end{array}$ & F & Sig. \\
\hline 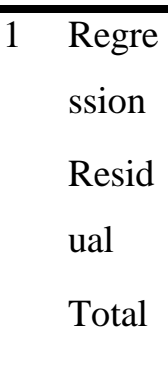 & $\begin{array}{r}1627.9 \\
56 \\
206.23 \\
4 \\
1834.1 \\
90\end{array}$ & 96 & $\begin{array}{r}542.65 \\
2 \\
2.148\end{array}$ & $\begin{array}{r}252 . \\
599\end{array}$ & $\begin{array}{r}.000 \\
\mathrm{~b}\end{array}$ \\
\hline
\end{tabular}

a. Dependent Variable: Kinerja karyawan

b. Predictors: (Constant), Kepuasan kerja,

Motivasi, Lingkungan kerja

Sumber: Hasil Penelitian, 2015 (Data Diolah)

Berdasarkan Tabel 4.26 di atas diperoleh 
bahwa nilai Fhitung (252.59) lebih besar dibandingkan dengan nilai Ftabel (2,70), dan sig. $\alpha(0,000 a)$ lebih kecil dari alpha 5\% $(0,05)$. Hal ini mengindikasikan bahwa hasil penelitian menolak H0 dan menerima H1. Dengan demikian secara serempak lingkungan kerja, motivasi dan kepuasan kerja berpengaruh signifikan terhadap kinerja karyawan pada PT Fega Marikultura.

\section{KOreIasi PrOduct MOment}

KOreIasi PrOduct MOment peneliti gunakan untuk mengetahui hubungan antara variabeI disipIin kerja $(\mathrm{X})$ dengan variabeI kinerja karyawan $(\mathrm{Y})$.

Berikut adaIah hasiI perhitungan k0reIasi

PrOduct M0ment menggunakan bantuan Pr0gram SPSS Ver. 24:

\section{C0rreIations}

\begin{tabular}{|l|l|l|}
\hline & Kinerj \\
& DisipIinKerja & $\begin{array}{l}\text { aKary } \\
\text { awan }\end{array}$ \\
\hline Pears0n C0rreIati0n & I & $.372^{* *}$ \\
Sig. (2-taiIed) & & .003 \\
N & $6 \mathrm{O}$ & $6 \mathrm{O}$ \\
\hline Pears0n C0rreIati0n & $.372^{* * *}$ & $\mathrm{I}$ \\
Sig. (2-taiIed) & .003 & \\
N & $6 \mathrm{O}$ & $6 \mathrm{O}$ \\
\hline
\end{tabular}

**. COrreIati0n is 5ignificant at the O.O1

IeveI (2-taiIed).
Berdasarkan tabeIdiatas dapat diketahui bahwa k0efisien k0reIasi pears0n ada hubungan k0reIasi p0sitif antara disipIin kerja dengan kinerja karyawan, yaitu 5ebesar $\mathrm{r}=0,372$ yang terma5uk kateg0ri RENDAH (o,20o -o,399).

\section{B. Analisa Deskriptif Pengaruh VariabeI \\ Bebas Terhadap VariabeI Terikat}

Untuk mempermudah pembahasan atas analisis yang dilakukan, akan dijelaskan pengaruh dari masing-masing variabel bebas yang meliputi lingkungan kerja, motivasi dan kepuasanan kerja terhadap kinerja karyawan.

1. Pengaruh Lingkungan kerja terhadap

Kinerja karyawan.

Hasil pengujian pengaruh lingkungan kerja terhadap kinerja karyawan secara statistik menunjukkan hasil yang signifikan. Hal itu ditunjukkan oleh nilai t hitung sebesar 12,613 pada $\mathrm{df}=100$ dengan nilai $\mathrm{t}$ tabel 1,98 . Besarnya nilai $\mathrm{t}$ hitung > t tabel mengindikasikan, bahwa pengaruhnya signifikan. Dengan demikian hipotesis yang menyatakan, bahwa lingkungan kerja berpengaruh langsung dan signifikan terhadap kinerja karyawan terbukti.

Lingkungan kerja adalah segala sesuatu yang ada di sekitar para pekerja dan 
dapat memepengaruhi dirinya dalam menjalankan tugas-tugas yang dibebankan (Nitisemito, 1996). Pada penelitian yang terdahulu oleh Kamaruzzaman tahun 2011, lingkungan kerja berpengaruh signifikan terhadap kinerja pegawai pada kantor Camat Sintang, Kabupaten Sintang.

2. Pengaruh Motivasi terhadap Kinerja karyawan.

Hasil pengujian pengaruh motivasi terhadap kinerja karyawan secara statistik menunjukkan hasil yang signifikan. Hal itu ditunjukkan oleh nilai t hitung sebesar 27,194 pada $\mathrm{df}=100$ dengan nilai t tabel 1,98. Besarnya nilai $\mathrm{t}$ hitung $>\mathrm{t}$ tabel mengindikasikan bahwa pengaruhnya signifikan. Dengan demikian hipotesis yang menyatakan bahwa motivasi berpengaruh langsung dan signifikan terhadap kinerja karyawan terbukti

karyawan yang termotivasi yang memiliki visi yang jelas dari pentingnya kualitas jasa terhadap perusahaan seharusnya dapat memberikan kualitas jasa (kinerja) yang tinggi (Bowen dan Lawler, 1992). Djumino dan M.Wahyudin (2002) menyatakan bahwa motivasi berhubungan positif dengan kinerja
3. Pengaruh Kepuasan kerja terhadap

Kinerja karyawan

Hasil pengujian pengaruh kepuasan kerja terhadap kinerja karyawan secara statistik menunjukkan hasil yang signifikan. Hal itu ditunjukkan oleh nilai t hitung sebesar 10,552 pada $\mathrm{df}=100$ dengan nilai $\mathrm{t}$ tabel 1,98. Besarnya nilai $\mathrm{t}$ hitung $>\mathrm{t}$ tabel mengindikasikan bahwa pengaruhnya signifikan. Dengan demikian hipotesis yang menyatakan bahwa kepuasan kerja berpengaruh langsung dan signifikan terhadap kinerja karyawan terbukti.

4. Pengaruh Lingkungan kerja, Motivasi dan Kepuasan kerja secara bersama-sama terhadap Kinerja karyawan.

Hasil pengujian pengaruh lingkungan kerja, motivasi dan kepuasan kerja secara bersama-sama terhadap kinerja karyawan secara statistik menunjukkan hasil yang signifikan. Hal ini ditunjukkan oleh nilai $\mathrm{F}$ hitung sebesar 252.59 pada $\mathrm{df}=100$ dengan $F$ tabel adalah 2.70. Besarnya nilai $\mathrm{F}$ hitung $>\mathrm{F}$ table mengindikasikan bahwa pengaruhnya signifikan. Dengan demikian hipotesis yang menyatakan bahwa pengaruh lingkungan kerja, motivasi dan kepuasan kerja secara bersama-sama berpengaruh langsung dan signifikan terhadap kinerja karyawan 
terbukti.

Jika dikaitkan dengan seberapa besar kontribusi variabel bebas terhadap variabel terikat, terlihat secara parsial yang paling dominan mempengaruhi yaitu sebesar $52,3 \%$ adalah variabel motivasi dibandingkan dengan variabel lainnya yaitu lingkungan kerja sebesar $0.4 \%$ dan Variabel lingkungan kerja sebesar 41.9\%. Hasil ini mengindikasikan, bahwa responden cenderung mengharapkan lingkungan kerja yang kondusif dalam mencapai kepuasan kerja yang positif serta dapat memotivasi pegawai sehingga dapat meningkatkan kinerja secara maksimal.

Bila mengacu pada teori-teori yang telah dijelaskan pada bab sebelumnya maka hasil penelitian tersebut sejalan dengan teori yang ada. Sebagaimana diungkapkan oleh Yukl (2002:31), bahwa pemimpin melalui kekuasaannya berusaha mempengaruhi, dan mengarahkan bawahannya untuk bekerja keras, memiliki semangat tinggi dan motivasi tinggi guna mencapai tujuan organisasi (kinerja). Disini terlihat jelas bahwa seorang pemimpin dengan gaya yang dimilikinya mempunyai peranan yang besar dalam mempengaruhi tinggi rendahnya kinerja yang dicapai.

Sedangkan terkait pengaruh lingkungan kerja terhadap kinerja hasil penelitian ini sesuai dengan pendapat Ruky (2001:41) yang menjelaskan bahwa terdapat sejumlah tujuan yang dapat dicapai dengan menerapkan sebuah sistem penilaian kinerja, diantaranya meningkatkan prestasi karyawan baik secara individu maupun sebagai kelompok sampai setinggi-tingginya yang pada gilirannya akan mendorong kinerja sumber daya manusia secara keseluruhan.

Hasil penelitian ini juga memperlihatkan bahwa adanya pengaruh motivasi terhadap kinerja adalah selaras dengan teori yang dikemukakan oleh Arnold and Feldman (1986, 25) yang menuliskan bahwa motivasi merupakan ketrampilan atau kapasitas sebenarnya yang dimiliki seseorang yang dituntut untuk secara efektif dapat meningkatkan kinerjanya.

\section{KesimpuIan}

Berdasarkan hasiI penelitian dan analisis data yang teIah diIakukan daIam peneIitian ini PT Fega Marikultura.maka penuIis mengambiI kesimpuIan sebagai berikut:

1. Pengaruh Lingkungan kerja terhadap 
Kinerja karyawan.

Hasil pengujian pengaruh lingkungan kerja terhadap kinerja karyawan secara statistik menunjukkan hasil yang signifikan. Hal itu ditunjukkan oleh nilai t hitung sebesar 12,613 pada $\mathrm{df}=100$ dengan nilai t tabel 1,98 . Besarnya nilai $t$ hitung > t tabel mengindikasikan bahwa pengaruhnya signifikan. Dengan demikian hipotesis yang menyatakan bahwa lingkungan kerja berpengaruh langsung dan signifikan terhadap kinerja karyawan terbukti.

2. Pengaruh Motivasi terhadap Kinerja karyawan.

Hasil pengujian pengaruh motivasi terhadap kinerja karyawan secara statistik menunjukkan hasil yang signifikan. Hal itu ditunjukkan oleh nilai t hitung sebesar 27,194 pada $\mathrm{df}=100$ dengan nilai $\mathrm{t}$ tabel 1,98. Besarnya nilai $\mathrm{t}$ hitung $>\mathrm{t}$ tabel mengindikasikan bahwa pengaruhnya signifikan. Dengan demikian hipotesis yang menyatakan bahwa motivasi berpengaruh langsung dan signifikan terhadap kinerja karyawan terbukti.

3. Pengaruh Kepuasan kerja terhadap

Kinerja karyawan

Hasil pengujian pengaruh kepuasan kerja terhadap kinerja karyawan secara statistik menunjukkan hasil yang signifikan. Hal itu ditunjukkan oleh nilai t hitung sebesar 10,552 pada $\mathrm{df}=100$ dengan nilai $\mathrm{t}$ tabel 1,98. Besarnya nilai $\mathrm{t}$ hitung $>\mathrm{t}$ tabel mengindikasikan bahwa pengaruhnya signifikan. Dengan demikian hipotesis yang menyatakan bahwa kepuasan kerja berpengaruh langsung dan signifikan terhadap kinerja karyawan terbukti.

4. Pengaruh Lingkungan kerja, Motivasi dan Kepuasan kerja kerja secara bersama-sama terhadap Kinerja karyawan.

Hasil pengujian pengaruh lingkungan kerja, motivasi dan kepuasan kerja secara bersama-sama terhadap kinerja karyawan secara statistik menunjukkan hasil yang signifikan. Hal ini ditunjukkan oleh nilai $F$ hitung sebesar 252.59 dengan $F$ tabel adalah 2.70. Besarnya nilai $\mathrm{F}$ hitung $>\mathrm{F}$ table mengindikasikan, bahwa pengaruhnya signifikan. Dengan demikian hipotesis yang menyatakan bahwa pengaruh lingkungan kerja, motivasi dan kepuasan kerja secara bersama-sama berpengaruh langsung dan signifikan terhadap kinerja karyawan terbukti.

\section{Saran}

Berdasarkan pembahasan dan kesimpuIan PT 
Fega Marikultura, maka saran dari penuli sekiranya dapat bermanfaat untuk perkembangan perusahaan serta dapat memberikan masukan bagi perusahan adaIah sebagai berikut:

1. Perusaha Pihak-pihak yang diberi kewenangan dalam hal meningkatkan lingkungan kerja pegawai hendaknya dapat ditingkatkan kualitasnya sehingga dapat memberikan manfaat sesuai yang diharapkan. Walaupun dalam hasil penelitian dalam hal kebisingan yang cukup mengganggu konsentrasi karyawan sedikit sekitar $1.6 \%$ saja, tapi tidak bisa dipungkiri harus diberikan solusi terbaik untuk mengurangi suara bising mesin diesel yang ada yang lebih kondusif dan nyaman, sehingga karyawan akan lebih betah tinggal. Dalam hal keamanan juga perlu ditingkatkan, adanya penambahan satuan pengamanan (Satpam), yang selama ini dua orang, perlu ditambah agar karyawan merasa aman berada dan tinggal di pulau Jukung.

2. Pimpinan perlu secara intensif melakukan evaluasi terhadap motivasi pegawai sehingga dapat terus terjaga kualitasnya. Hal tersebut dapat dilalukan melalui pelatihan internal maupun bekerjasama dengan pihak luar yang berkompeten atau melakukan studi banding untuk menambah wawasan. Disamping itu juga perlunya kontrol yang lebih cermat dalam hal perekrutan pegawai baru sehingga diperoleh SDM yang berkualitas dan sesuai dengan kebutuhan kinerja organisasi.

3. Kepada peneliti yang akan datang berharap hendaknya dapat melanjutkan penelitian ini khususnya terhadap faktorfaktor yang lain yang diduga mempengaruhi kinerja karyawan khususnya pada PT Fega Marikultura.

\section{DAFTAR PUSTAKA}

Anwar Prabu Mangkunegoro. 2001, Manajemen Sumber Daya Manusia Perusahaan, Remaja Rosdakarya, Bandung

Ambar Teguh Sulistiyani dan Rosidah. 2008. Manajemen Sumber Daya Manusia. Graha Ilmu, Yogyakarta

Arikunto, Suharsismi., 2002, Prosedur Suatu Penelitian; Pendekatan Praktek, Edisi Revisi V, Penerbit Rineka Cipta, Jakarta.

As'ad, 2003, Psikologi Industri, Liberty, Yogyakarta

Assauri, Sofjan. 2005. Manajemen Produksi dan Operasi (Edisi Revisi). Lembaga Penerbit Fakultas Ekonomi Universitas 
Indonesia:

Azwar., 2005, Pendayagunaan Sumber Daya Manusia secara Manusiawi, Penerbit Erlangga, Jakarta.

Bakowatur., 2003, Perilaku Organisasi Perusahaan, Salemba Empat, Jakarta.

Benyamin Molan ,2005, Manajemen Pemasaran, Edisi Keduabelas, Jilid 1, PT. Indeks

Djarwanto dan Pangestu Subagyo. 2003. Statistik Induktif. Yogyakarta: BPFE-. UGM

Friska, 2003, Organisasi dalam Sebuah Sistem, Fisipol-USU, Medan.

Fuad Mas`ud. 2004. Survai Diagnosis Organisasional, Konsep \& Aplikasi. Semarang: Badan Penerbit Universitas Diponegoro

Ghozali, Imam. 2005. Aplikasi Analisis Multivariate dengan program SPSS, Badan Penerbit Universitas Diponegoro, Semarang

Hasibuan, Malayu., 2008, Manajemen Sumber Daya Manusia, Penerbit:Bumi aksara, Jakarta.

Heidjrachman dan Husnan, 2002, Perilaku Organisasi, Penerbit Erlangga, Jakarta. Kartonegoro, 2006, Manajemen Sumber Daya Manusia, Penerbit Andi, Yogyakarta.

Lodge dan Derek, 2005, Prinsip-prinsip perilaku organisasi, Edisi V, alih bahasa Halida SE, dkk, Penerbit Erlangga, Jakarta.
Mathis dan Jackson, 2003, Perilaku Organisasi, Edisi X, Penerbit Andi, Yogyakarta.

Munandar, A. S., 2001, Psikologi Industri dan Organisasi, Penerbit UI-Press, Jakarta.

Nazir, Mohammad., 2003, Metodologi Penelitian, Ghalia Indonesia,

Pasaribu, V. L. D., Krisnaldy, K., \& Warasto, H. N. (2020). Pengaruh Gaya Kepemimpinan, Disiplin Kerja Dan Kompensasi Terhadap Kinerja Pegawai (Studi kasus kelurahan Pisangan Ciputat). Jurnal Disrupsi Bisnis: Jurnal Ilmiah Prodi Manajemen, Fakultas Ekonomi, Universitas Pamulang, 3(1).

Reksohadiprodjo, 2001, Organisasi Perusahaan Teori, Struktur dan Perilaku Edisi II, BPFE, Yogyakarta.

Robbins, 2006, Perilaku Organisasi, Indeks, Jakarta

Sedarmayanti, 2003, Prinsip-prinsip Perilaku Organisasi, Mandar Maju, Bandung.

Siagian, Sondang., 2000, Manajemen Sumber Daya Manusia, Penerbit Bumi Aksara, Jakarta.

Singarimbun dan Effendi, 1995, Metode Penelitian Survey, Edisi II, Penerbit PT. Pustaka LP3ES Indonesia, Jakarta.

Singarimbun, Masri. 2005.Metode Penelitian Survai. LP3ES, Jak

Sumarsono, Sonny, 2004, Muwu ‥set Sumber Daya Manusia, STIE YKPN, Page | 102 
JURNAL ПMПAH

(2)

(5) 5 (0 J O Jurnal Semarak,Vol. 3,No.3, OKTOBER 2020, Hal (82-102)

@Prodi Manajemen Fakultas Ekonomi Universitas Pamulang

\section{Yogyakarta}

Sunarto, 2005, Manajemen Sumber Daya

Manusia Strategik, Penerbit Amus,

Yogyakarta.

Umar, Husein., 2003, Metode Riset Bisnis, Edisi

I, PT. Gramedia Pustaka Utama,

Jakarta. 